\title{
Magnitude estimation of perceived distance over various distance ranges'
}

ROBERT J. VINCENT, ${ }^{2}$ BILL R. BROWN, ROBERT P. MARKLEY, and MALCOLM D. ARNOULT. Texas Christian University, Fort Worth, Texas 76129

Three groups of Os made magnitude estimation judgments of the apparent distance of a stationary space vehicle model under conditions simulating outer space. Psychophysical functions for three stimulus ranges were obtained. The exponents for the near and far stimulus ranges were 1.0. The power function exponent for the "full" range group was 0.48 . The psychophysical scales were compared to JND scales obtained in previous research. The results indicated that in all ranges investigated the power law is an appropriate description of the relationship between perceived and objective distance, but that distance range and the location of the range are important determinants of the psychophysical scale.

There have been few investigations concerned with scaling perceived distance as a function of objective distance. Gilinsky (1951) required two Os to bisect each one of 14 distances between $8 \mathrm{ft}$ and $200 \mathrm{ft}$ on a large flat lawn; the results are well described by a power function with a slope of 0.87 . The exponent was estimated by the present authors from an analysis of median judgments fitted by least squares.

In one phase of a larger study, Gruber (1954) required 20 Os to make half-distance judgments of six distance pairs, the stimuli being either $10-\mathrm{cm}$ or $15-\mathrm{cm}$ triangles viewed at distances between $6.4 \mathrm{ft}$ and $14.4 \mathrm{ft}$. Mean distance judgments were plotted as a straight line against objective distance in $\log$-log coordinates, the function having a slope of $n=1.02$ as determined by least squares.

Künnapas (1960) scaled distance over three objective ranges and found that the power function exponent decreased in an orderly fashion as the stimulus range increased. Pairs of 18 in. squares were presented to each $O$, who scaled distance by the method of ratio estimation. The ranges were as follows: (1) $3.3 \mathrm{ft}$ to $19.7 \mathrm{ft}$; (2) $6.6 \mathrm{ft}$ to $59.0 \mathrm{ft}$; and (3) $6.6 \mathrm{ft}$ to $68.9 \mathrm{ft}$. The exponents were $1.47,1.22$, and 1.16 , respectively.

The present study attempted to obtain a psychophysical function for distance utilizing an optically simulated large target (simulated size approximately $24 \mathrm{ft}$ high and $13 \mathrm{ft}$ in diam) located in a textureless environment at simulated distances along the saggital plane out to $12,800 \mathrm{ft}$. Further information about the range effect on the psychophysical function was also obtained.

\section{OBSERVERS}

Thirty-three Os volunteered to participate in this research. Each $O$ had $20 / 20$ vision or better (corrected, if necessary) as determined from an examination conducted by an optometrist. No $O$ had participated in similar research; the Os were not informed of the purpose of the research. Three experimental groups were formed from the pool of volunteers in a nonsystematic manner. Groups of 11 Os each scaled the full and far ranges, and $10 \mathrm{Os}$ scaled the near range. The data from one $O$ was disregarded since he failed to follow the instructions.

\section{APPARATUS}

Distance judgments were made in the NASA-TCU Space Vision Simulator. The opto-mechanical simulator offers a high-fidelity, threedimensional presentation of a space vehicle (Apollo Command and Service Modules) in a star-free outer space environment. The appropriate retinal sizes, binocular cues and relative brightness changes over a simulated range from $150 \mathrm{ft}$ to $20,000 \mathrm{ft}$ are generated by the device.

\section{PROCEDURE}

The Os participated in the experiment separately and were read the following instructions: "I am going to show you a spacecraft at various distances. Your task is to tell how far away it appears by assigning numbers to the distances. The first time that you see the target it will be at a distance you are to call '10.' Thereafter, you are to assign numbers proportional to your subjective impression of this first distance. For example, if the target appears to be twice as far away as the first target, assign to it a number of '20.' If it appears to be $1 / 5$ th as far, call it ' 2 ,' and so forth. I do not want you to restrict your response range. Use numbers as large or as small as you feel are necessary, including those less than " 1 ' (fractions or decimals) if you feel they are appropriate."

Three distance ranges were investigated:

(a) The target was presented at seven distances within the range $150 \mathrm{ft}$ to $20,000 \mathrm{ft}$ (full range) chosen so as to approximate a geometric series. The midpoint of the stimulus range, $1750 \mathrm{ft}$, was selected as the standard and was identified with the number " 10 " only once at the beginning of each session.

(b) Ten stimuli were presented at approximately equal logarithmic intervals ranging between $5500 \mathrm{ft}$ and $10,000 \mathrm{ft}$. The standard for this far range was at $7200 \mathrm{ft}$.

(c) For the near range, 10 stimuli were shown at approximately equal logarithmic intervals, ranging from $500 \mathrm{ft}$ to $5,000 \mathrm{ft}$, with a standard at $1800 \mathrm{ft}$.

For all three experimental groups, the targets were presented in irregular order in four separate series. An intertrial interval of $10 \mathrm{sec}$ was required to change distances. During this time a shutter occluded the visual scene.

\section{RESULTS}

Scale values were obtained from the geometric means of the first two of four responses to each stimulus, taken across Os. Scale values for the far and near distance ranges conformed to a power function with an exponent of 1.0. For these ranges perceived distance is thus directly related to physical distance. The functions were fitted by least squares.

A distinctively curvilinear function was obtained for the full range results. A modified power function

$$
R_{D}=\left(I_{D}-I_{D_{O}}\right)^{0.48}
$$

was found to fit the data. Here, perceived distance $\left(R_{D}\right)$ grows approximately as the square root of objective distance $\left(I_{D}\right)$. The curve was fitted by the procedure devised by Ekman $(1961) . I_{D_{O}}$ is a constant value $(300 \mathrm{ft})$ which is subtracted from each stimulus value to produce a linear function. For several other continua the constant has been considered as the "effective" threshold (Stevens, 1959; Scharf \& Stevens, 1960), but $I_{D_{O}}$ is too large for the term "threshold" to be an appropriate label for the constant in the present study.

Table 1 lists the interquartile ranges of responses for all Os across all comparison stimuli, showing the number of JNDs involved in each stimulus range, and the exponent for each stimulus range. The JND data were taken from a study by Vincent, Brown, \& Arnoult (1968). The response ranges were

Table 1

Stimulus Range, Response Range, and Exponents for Three Groups of Observers

\begin{tabular}{llll}
$\begin{array}{l}\text { Stimulus } \\
\text { Range }\end{array}$ & $\begin{array}{l}\text { Interquartile Range of } \\
\text { Magnitude Estimations }\end{array}$ & No. of JNDs & Exponent \\
\hline
\end{tabular}

Full Range

Q1 Q3

$150-20,000 \mathrm{ft} \quad 4 \quad 20.5$

190

0.48

Far Range

$5500-10,000 \mathrm{ft} 9$

12

17

Near Range

$500-5000 \mathrm{ft}$
25

90 
not directly related to stimulus ranges. Rather, the response ranges appeared to reflect an interaction of both stimulus range and the location of the stimulus range along the stimulus continuum. The Os judging the far range had a smaller amount of response dispersion than did the Os judging the full and near ranges. The amounts of response dispersion in the latter two ranges were similar.

If the near-points of the full and near ranges are considered to be sufficiently similar as to be equal, it follows that as the stimulus range increases, the exponent describing the corresponding distance scale decreases. Such a trend was noted by Künnapas (1960). This relationship also holds when the near-point is markedly displaced (to $5500 \mathrm{ft}$ in the far target range). The results, however, are not consistent with the contention of Kunnapas (1960) that, as the ratio of the maximal stimulus in the range to the minimal stimulus increases, the exponent decreases.

An additional view of the range effect was obtained by computing functions relating magnitude estimates to summated JND scales (data from Vincent, Brown, \& Arnoult, 1968). The least squares functions were

$$
\log R_{D}=.012(J N D)-.253
$$

for the near range,

$$
\log R_{D}=.016(J N D)-1.654
$$

for the far range, and

$$
\log R_{D}=.008(J N D)+.079
$$

for the full range. $R_{D}$ refers to magnitude estimations and JND to the number of JNDs relative to $150 \mathrm{ft}$. These functions suggest that discriminative sensitivity is related to the specificity of psychological scales, since equal response ratios seem to be derived from equal discrimination differences. It should be recalled that for prothetic continua (Stevens, 1957), such as loudness, brightness, and perceived distance, the magnitude of the JND increases with an increase in stimulus intensity. Therefore, the number of JNDs within a range are specific both to the extent of the range as well as to the location of that range on the stimulus continuum.

\section{DISCUSSION}

The results indicate that for all ranges investigated the power law is an appropriate description of the relationship between perceived and objective distance. Distance range and the location of the range, however, are important determinants of the parameters of the psychophysical scale.

The role of stimulus range has been demonstrated by a number of authors concerned with subjective length of lines, subjective area, apparent distance, brightness, loudness, heaviness, and numerosity (Engen \& Levy, 1958; Schickman, 1960; Stevens, 1958; Björkman \& Strangert, 1960; Künnapas, 1960; Strangert, 1961; and Ekman \& Sjoberg, 1965). In each instance, the exponent of the scale decreased as stimulus range increased. Künnapas (1960) mentioned that his Os tended to apply a relatively constant response range regardless of the stimulus (distance) range, thus producing a decrease in the value of the exponent as stimulus range increased. This observation is consistent with the decrease in slope as one proceeds from the near to the full distance range in the present study. The response ranges (in terms of overall interquartile ranges) were quite comparable. Moreover, the functions relating scale values to the summated JND data support such a position; the slope decreased with increased stimulus range, indicating that the rate at which estimates increase diminishes as the number of discriminable points grows.

As for the far distance range, the response range was substantially smaller than in the other conditions. This reflects, at least in part, the difficulty encountered in discriminating differences at these distances. The slope of the function relating magnitude estimates to the JND scale was largest in this instance, suggesting that Os were in fact functioning with limited discriminative ability.

The relationships reported here between summated JND scales and magnitude estimation scales are consistent with previous findings (Ekman and Sjoberg, 1965). The authors feel, however, that it is more meaningful to consider the JND scale to be the independent rather than the dependent variable.

In summary, the overall extent of the stimulus range alone does not determine the psychophysical scale; one must also consider the number of perceptively different stimuli within the range. This combination of factors has the same role in other continua as Vincent (1967) has recently demonstrated with respect to softness and apparent distance of a tone.

\section{REFERENCES}

BJÖRKMAN, M., \& STRANGERT, B. The relationship between ratio estimation and stimulus dispersion. Report of the Psychology Laboratory, University of Stockholm, 1960, No. 81.

EKMAN, G., \& SJÖBERG, L. Scaling. In P. W. Farnsworth and $O$ McNemar (Eds.), Annual review of psychology, Vol. 16. Palo Alto, Calif.: Annual Review, Inc., 1965. Pp. 451-474.

EKMAN, G. A simple method for fitting psychophysical power functions. Journal of Psychology, 1961, 51, 343-350.

ENGEN, T., \& LEVY, N. The influence of context on constant-sum loudness judgments. American Journal of Psychology, 1958, 71, $731-736$

GILINSKY, A. S. Perceived size and distance in visual space. Psychological Review, 1951, 58, 460-482.

GRUBER, H. E. The relation between perceived size and perceived distance. American Journal of Psychology, 1954, 67, 411-426.

KÜNNAPAS, T. Scales for subjective distance. Scandinavian Journal of Psychology, 1960, 1, 187-192.

SCHARF, B., \& STEVENS, J. C. The form of the loudness function near threshold. In Proceedings of the 3rd International Congress of Acoustics. Amsterdam: Elsevier, 1961. Pp. 80-82.

SCHICKMAN, G. M. Brief illumination and visual temporal resolving power. Unpublished doctoral dissertation, Harvard University, 1960.

STEVENS, J. C. Stimulus spacing and the judgment of loudness. Journal of Experimental Psychology, 1958, 56, 246-250.

STEVENS, S. S. On the psychophysical law. Psychological Review, 1957, 64, 153-181.

STEVENS, S. S. Tactile vibration: Dynamics of sensory intensity. Journal of Experimental Psychology, 1959, 57, 210-218.

STRANGERT, B. A. A validation study of the method of ratio estimation. Report of the Psychology Laboratory, University of Stockholm, 1961, No. 95.

VINCENT, R. J. A revised physical correlate theory relating softness to perceived distance. Unpublished doctoral dissertation. Texas Christian University, August, 1967.

VINCENT, R. J., BROWN, B. R., \& ARNOULT, M. D. Distance discrimination in a simulated space environment. NASA CR 73-205, January, 1968.

NOTES

1. This research was supported by Contract NAS 21481 and Grant NGR 44009018 from the National Aeronautics and Space Administration to Texas Christian University; M. D. Arnoult, Principal Investigator. A longer version of the paper appeared as Document NASA CR 73-172, dated January 1968.

2. Now residing in Waldorf, Md. 